\title{
Game Theory Applied in the Management of Electric and Electronic Equipment Waste in Brazil
}

\section{Araujo MV*, Silva Marins FA, Santos MA, de Oliveira UR and Muniz Júnior J}

Sao Paulo State University - UNESP, Av. Ariberto Pereira da Cunha, 333, Guaratingueta - SP, 12516410, Brazil

*Corresponding author: Araujo MV, Sao Paulo State University-UNESP,Av. Ariberto Pereira da Cunha, 333, Guaratingueta - SP, 12516410, Brazil, Tel: +551156270439; E-mail: marcusvinicius@vwa.com.br

Received date: Mar 04, 2017; Accepted date: Mar 06, 2017; Published date: Mar 08, 2017

Copyright: (c) 2017 Araujo MV, et al. This is an open-access article distributed under the terms of the Creative Commons Attribution License, which permits unrestricted use, distribution, and reproduction in any medium, provided the original author and source are credited.

\begin{abstract}
Economic and environmental crises appear to increasingly come from similar exogenous origins, such as market failures, and endogenous sources, such as poor management of scarce natural resources. Notably, the establishment of PNRS (National Policy of Solid Waste) in Brazil led to the development of reverse logistics (RL) practices for various economic sectors, particularly electrical and electronic equipment. This paper focuses on this question and presents a quantitative evaluation of possible economic results that could be obtained using Game Theory in a negotiation between electronic manufacturers and a cooperative of collectors/recyclers of waste electrical and electronic equipment (WEEE). This article shows that there is a possibility of eliminating market failures and improving the management of resources to obtain optimal WEEE management through the implementation of Economic Game Theory along with the Coase Theorem. The discussion highlights the importance of choosing WEEE management tools in Brazil, including criteria for potentially negotiating between economic agents associated with waste.
\end{abstract}

Keywords: Logistics; Waste electrical and electronic equipment; Coase theorem; Pareto balance; Game theory

\section{Highlights}

Game Theory and Coase theorem give efficiency to the management of WEEE in Brazil.

It is possible to reach a goal of recycling WEEE without government intervention.

Nash Bargaining Model is more efficient than Pareto Balance for WEEE management.

The proposed model depends on changes in Brazilian politics of solid waste.

It is expected to develop studies using other economic instruments.

\section{Introduction}

The global economic crisis, which began in 2007, revealed weaknesses in the financial system that not only included exogenous factors, such as self-regulating market inefficiency, irrationality of agents and asymmetry of information, but also endogenous factors, including speculation, the lack of perception of imminent economic disaster and widespread distrust [1].

Ref. [2] suggested that economic growth is deeply linked and limited by natural resources on the planet; similarly, Ref. [3] proposed inserting social environmental factors in the model of economic growth to optimize stewardship.

Ref. [4] highlighted the population's current explicit preferences and the pressures on the stocks of natural resources, producing improvised and short-term solutions. These solutions invariably lead to external costs, within and between nations, such as the case of Electric and
Electronic Equipment Waste (WEEE). According to Ref. [5], such externalities show a mimesis in which the environmental crisis comes from the same exogenous and endogenous factor generators of the economic crisis.

WEEE management is influenced by these factors, and stakeholders in this market disagree on certain points. According to Ref. [6], a disagreement occurs and the value of the good intensifies, generating disputes that can cause market imperfections. This fact shows the need for aligning concerns in the WEEE market that can maximize the benefits to lower costs for all stakeholders who are willing to cooperate to reach optimal economic and environmental outcomes. In Brazil, the establishment of the PNRS (National Policy of Solid Waste) in 2010 and the formalization of reverse logistics (RL) created a propitious environment to shape the management strategies of WEEE to utilize economic tools and generate learning curves [7]. Thus, searching for new strategies of natural resource consumption is necessary given the economic and environmental crises.

Ref. [8] argue that strategic decisions result in payoffs for all attendees of a specific scenario that can be called a Game. However, it is necessary to align the use of economic tools in WEEE management with the coordinate actions of stockholders in this Game.

Such coordination implies an equilibrated agreement, known as Pareto's Optimum [9], because no player can raise their level of payoff without impairing other players. It is possible to efficiently manage WEEE in RL environments, a goal of PNRS, and add in properties of symmetry, independence and invariance that are intrinsic to the Game Model of Cooperative Bargaining, one of the most important models in Game Theory [10].

Therefore, the aim of this paper was to quantitatively evaluate the economic results of a negotiation between a manufacturer of electric and electronic equipment that practices RL of WEEE and a cooperative of collectors/recyclers of WEEE. We utilized Game Theory after 
applying Pareto's Optimum concept from the arbitration function of Nash, according to Ref. [10]. In brief, the adoption of Game Theory together with economic tools uses the Coase Theorem [11]. This quantitative evaluation takes advantage of the perception that actual WEEE management in Brazil can achieve better environmental goals in terms of RL application at lower costs.

The proposed method was applied to a scenario formed by a manufacturer of electric and electronic equipment's and a cooperative of collectors/recyclers of WEEE that compare their marginal costs and benefits in practicing RL of WEEE. In this situation, these two agents could perform an economic analysis, alternating property rights on WEEE, seeking a strategic consensus that could be obtained through an economic cooperative game.

The article is organized as follows. The second section lists the criteria for choosing management tools in WEEE that achieve established environmental goals in Brazil using the law 12,305/2010, lowering societal costs. The third section shows a latosensu view about the Coase Theorem and strategic cooperative positioning. The fourth section shows Nash's Bargaining Model utilized in this paper. The fifth section shows a PNRS (National Policy of Solid Waste) diagnostic in terms of management processes and identifies congenital acquired pathologies. Given the conditions identified for PNRS (National Policy of Solid Waste) in Brazil and the criteria for choosing cost-effective management tools, the sixth section demonstrates a simulation of scenarios of manufacturers of electric and electronic equipment and a cooperative of collectors/recyclers of WEEE in which Game Theory (with Pareto's Optimum concept) is utilized with the Coase Theorem. This same section includes a discussion of the simulation results. The seventh section shows the conclusions and limitations for the conflicts of interest established in the research scenario and the continuous expectations in studies of economic tools in WEEE management, ending with bibliographical references.

\section{The Importance of the Choice of WEEE Management Tools}

In solid waste management and particularly the management of WEEE, choosing instruments is critical for efficient allocation. Such optimal allocation is even more necessary due to the high value of metals present in WEEE after recycling [12]. In solid waste management and particularly the management of WEEE, choosing instruments is critical for efficient allocation. Such optimal allocation is even more necessary due to the high value of metals present in WEEE after recycling [12]. Nations such as Germany, Sweden, Switzerland, Norway, and Denmark have a solid foundation for managing these wastes in their WEEE management systems, ensuring economic benefits at scale. Such nations utilize well-planned and executed RL, imposing costs to the polluters through applying principles of extended responsibility to the equipment producers to avoid waste at the end of their products' lives [13]. Similarly, Ref. [14] highlight the fact that the USA obtains the maximum economic advantage from WEEE along with minimal environmental damage, by beginning to attribute larger responsibilities to consumers of electric and electronic equipment, evoking the concept of the life cycle of products. The following criteria should be considered for this choice, adapted from Ref. [15] capacity of achieve environmental goals determined in PNRS (National Policy Solid Waste - environmental effectiveness), capacity to reach the equilibrium point (economic efficiency), achieve PNRS goals by lowering private and social costs (economic efficiency), promote social benefits (equity), have political acceptability, be feasible in management terms and permanently encourage further recovery of WEEE constituents. Therefore, the choice of WEEE management tools must observe these criteria to price electronics and their constituents after recycling according to their rarity, maximizing societal welfare and encouraging the continuous development of WEEE recycling technologies, further generating additional revenue for those involved with WEEE. The choice of WEEE management tools is also linked to globalization. The establishment of solid waste policies in each nation is invariably a result of particular decisions based on the consumption and production of electronics in each nation. Despite the existence of national sovereignty, Ref. [16] showed that sustainability cannot be considered separately and that it must be viewed as a worldwide product. The choice of WEEE management tools defines a set of strategies that, in a globalized world, should seize the opportunities seeking equilibrium. Such an equilibrium will be elaborated further from the concept of a cooperative strategic positioning, extended by Ref. [9] and known as Pareto's Equilibrium. Ref. [17] confirms the need for global sustainable development in globally standardized management methods of WEEE to maximize the benefits and reduce social-environmental costs. The worldwide perspective is shown in Frame 1, presenting the governmental policies and existence of practices in Brazil and in countries that are considered too strongly influence WEEE management across five continents [14,18-22]. An analysis of Table 1 identifies the lack of connectivity between the previously described strategies.

\begin{tabular}{|c|c|c|c|c|c|c|}
\hline \multirow{2}{*}{ Countries } & \multicolumn{5}{|l|}{ Strategy } & \multirow[b]{2}{*}{$\begin{array}{l}\text { Illegal } \\
\text { commerce } \\
\text { WEEE }\end{array}$} \\
\hline & Guiding Principle & $\begin{array}{l}\text { Management tool for } \\
\text { Logistics }\end{array}$ & $\begin{array}{l}\text { Existence of } \\
\text { Logistics } \\
\text { Manager } \\
\text { Fund }\end{array}$ & $\begin{array}{l}\text { Defining } \\
\text { responsibilities of } \\
\text { actors }\end{array}$ & $\begin{array}{l}\text { Hazardous } \\
\text { substances } \\
\text { limiting } \\
\text { production }\end{array}$ & \\
\hline Brazil & $\begin{array}{l}\text { Shared } \\
\text { Responsibility }\end{array}$ & Non-existent & Non-existent & Non-existent & No & Uncertain \\
\hline $\begin{array}{l}\text { USA- } \\
\text { California }\end{array}$ & $\begin{array}{l}\text { Extended } \\
\text { Responsibility }\end{array}$ & Taxes over Consumers & $\begin{array}{l}\text { Government } \\
\text { Fund }\end{array}$ & $\begin{array}{l}\text { Only } \\
\text { Manufacturers }\end{array}$ & No & Exporter \\
\hline South Africa & Non- existent & Non-existent & Non-existent & Non-existent & No & Importer \\
\hline
\end{tabular}


Page 3 of 9

\begin{tabular}{|l|l|l|l|l|l|}
\hline China & $\begin{array}{l}\text { Extended } \\
\text { Responsibility }\end{array}$ & $\begin{array}{l}\text { Taxes } \\
\text { manufacturer } \\
\text { importers }\end{array}$ & $\begin{array}{l}\text { over } \\
\text { and }\end{array}$ & $\begin{array}{l}\text { Government } \\
\text { Fund }\end{array}$ & Only \\
\hline Australia & $\begin{array}{l}\text { Non- } \\
\text { existent }\end{array}$ & Non-existent & Non-existent & Non-existent \\
\hline Switzerland & $\begin{array}{l}\text { Extended } \\
\text { Responsibility }\end{array}$ & $\begin{array}{l}\text { Taxes } \\
\text { manufacturer } \\
\text { consumers and }\end{array}$ & $\begin{array}{l}\text { Manufacturers } \\
\text { Association }\end{array}$ & Yes & Yes \\
\hline
\end{tabular}

Table 1: Policies and practices across five continents (2015).

Regulatory instruments are the main advantages, according to Ref. [23], in predicting results and the ease of administration in sources demanding standard patterns of release and environmental quality. As one advantage, there is a fundamental dependence on surveillance, the relationship between benefits and costs of control measures and a lack of incentive for additional pollution control measures. In the case of economic instruments, Ref. [24] lists the advantages that encourage the continued development of pollution control technologies, generating revenue for governments, the flexibility of adopting pollution abatement technologies and the potential for achieving environmental goals at lower costs. However, the same author stresses that economic instruments are complexly administered, and a significant portion of resistance polluters bet on the inefficiency of supervision and high-risk activities, as in the case of nuclear plants. Table 2 compares the management using regulatory tools and economic tools.

\begin{tabular}{|l|l|l|}
\hline Criteria to choose & Tools & \\
\cline { 2 - 3 } & Regulatory & Economic \\
\hline Environmental effectiveness & yes & yes \\
\hline Economic efficiency & no & yes \\
\hline Equity & no & yes \\
\hline Acceptability policy & yes & not always \\
\hline Administrative feasibility & yes & not always \\
\hline Encouraging additional controls & no & yes \\
\hline
\end{tabular}

Table 2: Comparison between regulatory tools and economic tools.

According to Frame 2, it is possible to infer that WEEE management-related policies should prioritize the use of economic tools to produce results that achieve reduction goals, reutilization and recycling to lower private and social costs. In this manner, it is possible to take advantage of improvements to population welfare within environmental conservation.

\section{Coase Theorem and Cooperative Strategic Positioning}

According to Ref. [25], governments are not immune to failure, possibly due to lack of information, whether by corporate interests or political direction. Therefore, achieving social optimums does not depend exclusively on eliminating market failure but also on internalizing externalities that might be resolved by defining property rights. Such thinking reflects the analysis performed and published in 1960 by Nobel Prize economics winner in 1991 Ronald Coase that theorized about the gains by internalizing external costs that might be larger than damages, just by defining the rights or properties of a certain resource. In this context, the Coase Theorem proposes that governments should create ways for economic agents to negotiate free environmental goods to create transaction conditions defined by property rights. For Coase, the lack of defining property rights would be the root cause of the loss of welfare, considering that the inexistence of the transaction costs hypothesis would be preferable to the negotiation that directly occurs between economic agents without government intervention [26]. The possibility of applying the Coase Theorem in WEEE management and considering the inclusion of RL in PNRS leads to the perception that such economic agents define WEEE property rights and have strategies that must be induced to cooperation to realize the results of maximized gains in this market. To mathematically assist the implementation of the Coase Theorem, resorting to Game Theory in managing WEEE is possible according to Ref. [10,27] in the Applied Mathematics sector dedicated to the theoretical understanding of the processes of rational agent decisions that interact in a strategic way. Ref. [27] highlights that a Game can be defined as a contest between players resulting in a trivial solution and not necessarily involving a bargain between players. According to Ref. [10], the games have varying strategic positioning and consider the likely reactions of the economic agents involved. Ref. [28] rank the strategic equilibrium positioning as cooperatives, non-cooperatives or predatory. To achieve the environmental goal defined by PNRS of lowering societal costs, this paper will focus on cooperative strategies and therefore will analyze the Pareto's Equilibrium and Nash's Equilibrium. In the case of Pareto's Equilibrium, the cooperation between economic agent participants of the WEEE market could achieve better results from each agent separately because not having knowledge about other market players' decisions would be worse. Information sharing about respective interests, conditions, functions and objectives allows one to reach an equilibrium point called Pareto's Optimum characterized by the fact that none of the players can improve their results without injuring other players' results. However, in a free market environment proposed by Coase Theorem, other prerogatives must be observed in order to reach not only one optimal solution but rather a more equilibrate optimum solution that expresses the precepts of a perfectly competitive market [28]. Such prerogatives not only consider the Pareto's Optimum but also market conditions that cover symmetry, independence and invariance. These four axioms are satisfied by Nash's Bargaining Model [6].

\section{Nash’s Bargaining Model}

To aid both the definition of Pareto's Equilibrium concept, established according to Nash's conception (1950) and Nash's 
Bargaining Model, consider that $S$ is a set of viable strategies that specifies the actions in a game with $\mathrm{N}$ players and that $\mathrm{u}=\left(\mathrm{u}_{1}(\mathrm{x}) \ldots \mathrm{u}_{\mathrm{n}}(\mathrm{x})\right)$ is a payoff function for each player. The variable $\mathrm{x}$ defines the strategic action adopted by the players. Nash's Equilibrium can be defined as a situation in which no players improve their gains that unilaterally change their strategies.

For a mathematical definition of this concept, consider that $\mathrm{X}-\mathrm{I}$ is the set of strategies from all players with the exception of player $i$. When each player $i\{1 \ldots, n\}$ selects their strategy xi resulting in the set of strategies $\mathrm{x}=\left(\mathrm{x}_{1} \ldots, \mathrm{x}_{\mathrm{n}}\right)$, then player $\mathrm{i}$ obtains the payoff $\mathrm{u}_{\mathrm{i}}(\mathrm{x})$, where the payoff depends on the strategy selected by player $i$ and the adopted strategies selected by the other opponents.

A set of strategies $x^{*} S$ is characterized as Nash's Equilibrium if no other strategy is better for player $i$ in which the opponents choose the best strategies: $\mathrm{i}, \mathrm{x}_{\mathrm{i}} \mathrm{S}_{\mathrm{i}}, \mathrm{x}_{\mathrm{i}} \neq \mathrm{x}_{\mathrm{i}}^{*}: \mathrm{u}_{\mathrm{i}}\left(\mathrm{x}_{\mathrm{i}}^{*}, \mathrm{x}_{-\mathrm{i}}^{*}\right) \geq \mathrm{u}_{\mathrm{i}}\left(\mathrm{x}_{\mathrm{i}}, \mathrm{x}_{-\mathrm{i}}{ }^{*}\right)$.

In the hypothesis in which we consider two players $(\mathrm{N}=2)$ with their respective payoffs $\mathrm{u}_{1}(\mathrm{x})$ and $\mathrm{u}_{2}(\mathrm{x})$, the result previewed by Nash's Bargaining Model embraces the where $d=\left(d_{1}, d_{2}\right)$ is called the disagreement point [37].

The disagreement point represents an initial state before the negotiation in which each player exposes information about the minimum desirable levels of payoff in a non-cooperative situation and searches together for the ways of negotiating set actions (cooperative strategies) that improve the profitability for both players.

The results predicted by Nash's Bargaining model are widely accepted because they satisfy the axioms known as Pareto's Optimum, symmetry, invariance, and independence, which are conditions that represent an ideal market.

For example, for two players in Pareto's Equilibrium, characterized by payoffs for players 1 and $2, u_{1}(x)$ e $u_{2}(x) S$, se $u_{2}>u_{1}$, then $f(S, d) \neq$ $\mathrm{u}_{1}$, where "d" is the disagreement point and would imply the need to find an optimum solution of payoffs in $\mathrm{S}$ for both players.

The condition of $\mathrm{S}$ being a symmetric set occurs when the disagreement points $d_{1}$ and $d_{2}$ are equal and Nash's function $f_{1}$, with the horizontal axis associated with payoff $\mathrm{u}_{1}$ and the vertical axis associated with payoff $\mathrm{u}_{2}$, will be a Nash's function $\mathrm{f}_{2}$ with the vertical axis associated with payoff $\mathrm{ul}$ and the horizontal axis associated with payoff $\mathrm{u}_{2}$.

In this situation, $f_{1}(S, d)=f_{2}(S, d)$ guarantees the inclusion of all relevant parameters for the Bargaining. Inserting the dependence of irrelevant alternatives, $T$, it is possible to infer that, if TS e f $(S, d) T$, then $f(T, d)=f(S, d)$ and the solution should not be influenced by the choice of irrelevant alternatives during the negotiation between the parts.

Therefore, to reach the most equilibrate optimum point, it is necessary to associate the previously listed axioms and the invariance by linear transformations that establish that the solution obtained is independent of any scale [27].

\section{Pathologies of PNRS on management of WEEE in Brazil}

According to the classification of the Ministry of Development, Industry and Foreign Trade (2015), the electronic supply chain holds the following four lines of products: white line composed by refrigerators, freezers, stoves, air conditioners and washers; green line consisting of computers, printers and mobile phones; blue line consisting of mixers, blenders, electric irons, drills, hairdryers, juicers, vacuum cleaners, coffee makers; and the brown line consisting of televisions and other audio products and video. Considering just the waste generated from the post-consumption of these products, the estimated generation of WEEE in Brazil for the year 2015 is approximately $1,247.76$ thousand tons of WEEE. The magnitude this waste represents approximately $2 \%$ of all urban solid waste generated in Brazil.

The importance of this waste can be measured through the sustainability tripod - triple bottom line - where the economic question can be expressed by the quotient of 3.48 between the generation of WEEE (in kg) and the Brazilian GDP (Gross Domestic Product) in 2013 [29]. The social question is expressed by the health risks of people by manipulating dangerous substances in recycling [30] beyond the possibility of generating WEEE management jobs due to the high economic value of their constituents [31].

Completing the tripod of sustainability, there is the environmental question that expresses the risks involved with soil contamination, water and air due to the presence of heavy metals, polychlorinated biphenyls and other composts components in WEEE [32].

The principle of shared responsibility in the post-consumption products, arising from Article 225 of the Brazilian Federal Constitution of 1988, according to Ref. [33], is the main message of Law No. 12,305/10 (establishing the PNRS) and its Decree Regulatory No. $7,404 / 10$.

The PNRS integrates and reinforces other regulatory instruments of solid waste management as the CONAMA Resolution No. 258/99 (post-consumer tires), CONAMA Resolution No. 362/05 (post consumption of lubricating oils), CONAMA Resolution No. 401/08 (post-consumer batteries), and the CONAMA Resolution No. 237/97 (environmental licensing). Figure 1 summarizes the PNRS as a subset of the Brazilian Federal Constitution.

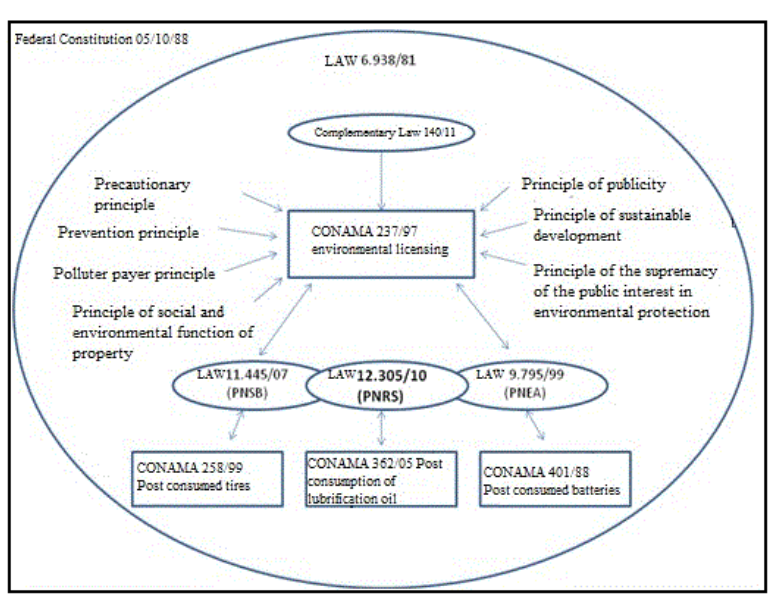

Figure 1: National Policy on Solid Waste as a subset of the Brazilian Federal Constitution.

Of note, Brazil is the largest WEEE generator among the emerging countries (UNEP), making PNRS an extremely important tool, and it is therefore relevant for an investigation into the existence of conditions for the conception of PNRS (congenital) or by applying the PNRS in Brazil (acquired). Moreover, the impacts of such pathologies imply externalities (Morse-Jones) that need to be identified to be 
minimized or eliminated, under penalty of becoming ineffective to PNRS.

In terms of design, the PNRS is identified here as a congenital pathology with a lack of definition for WEEE. Without defining the type of waste, management is impaired due to subjectivity recognized in classifying WEEE according to NBR 10,004/04.

Other pathologies of the same genus identified in PNRS are defining waste management mainly based on regulatory instruments totaling 14 forms of command and control (Law No. 12,305, Article 7. 2010) and only three groups of economic tools.

Ref. [33] argues that Article 42 of Law No. 12,305/2010 promotes the use of economic tools as inducement measures and for funding allowances to provide government interference even in the Brazilian Federal Constitution to address Article 170. Specifically, there is no mention of the source of funds for applying economic instruments.

In the case of RL, despite the prominence in PNRS, there are no predictions of penalty to consumers who do not cooperate with electronic manufacturers and who are required to practice RL. This fact exposes the uncertainty of effectiveness of the process for the lack of consumer commitment by establishing an obtainable pathology.

This finding may lead to conflicts of interest among manufacturers of electronic equipment and recycling cooperatives of WEEE, for example. Similarly, Ref. [35] describes the possibility of exporting hazardous waste by the lack of clarity and depth on the issue of recycling and the lack of definition regarding the supply of symmetric information of the functions of each actor in WEEE management in addition to core issues such as the practice of planned obsolescence of electronic products and guidance to reduce electronics.

Related to congenital pathologies and the operation of PNRS in Brazil, there are unfavorable external points and unfavorable internal points, observed in a scenario analysis using the SWOT matrix for WEEE management, as shown in Table 3.

\begin{tabular}{|c|c|c|}
\hline & Favorable & Unfavorable \\
\hline $\begin{array}{l}E \\
X \\
T \\
\text { E } \\
\text { R } \\
\text { N }\end{array}$ & $\begin{array}{l}\text { Respect for the general principles of environmental law; } \\
\text { Integrated management and cooperation among federal agencies, the business } \\
\text { sector and other segments of society; } \\
\text { Prohibition of the allocation or final disposal of solid waste or waste on beaches, } \\
\text { at sea or in any water bodies; in natura outdoor (excluding mining); burning } \\
\text { outdoor or in containers, plant and equipment not licensed for this purpose; } \\
\text { Prohibition of the importation of hazardous waste and tailings, although for } \\
\text { treatment, renovation, reuse, recycling or recovery }\end{array}$ & $\begin{array}{l}\text { Lack of definition as to what is WEEE; } \\
\text { Waste management fundamentally based on } \\
\text { Regulatory instruments; } \\
\text { Possibility of exportation of hazardous waste; - Lack of symmetric } \\
\text { information on the functions of each actor in the WEEE management; } \\
\text { Lack of incentive to the practice of planned obsolescence of electronic } \\
\text { products; } \\
\text { Lack of incentive to reduce the electronics consumerism. }\end{array}$ \\
\hline & $\begin{array}{l}\text { Criminalization of poor management of solid waste, including omission and } \\
\text { abandonment of waste; } \\
\text { Imposition to manufacturers, importers, distributors and marketers the obligation } \\
\text { to structure and implement reverse logistics systems for WEEE. }\end{array}$ & \\
\hline $\begin{array}{l}\text { I } \\
\text { T } \\
\text { E } \\
\text { R } \\
\text { N } \\
\text { A }\end{array}$ & $\begin{array}{l}\text { Institution of necessity for sectoral agreements between government, } \\
\text { manufacturers, importers, distributors or dealers giving a sense of shared } \\
\text { responsibility for the product life cycle; } \\
\text { Coverage of activities allowed in the environmental licenses permits reducing the } \\
\text { participation of unprepared people in WEEE management chain; } \\
\text { Encouraging the publication of the ABNT/NBR 16,156/13 establishing } \\
\text { requirements for the protection of the environment and control risks to the } \\
\text { health / safety of the people involved with reverse manufacturing of WEEE; }\end{array}$ & $\begin{array}{l}\text { Joint actions involving government may fail if few interests outweigh } \\
\text { interests of the community; } \\
\text { Increased costs due to the need for environmental licensing for WEEE } \\
\text { transport to the generators; } \\
\text { Increased costs due to the need for environmental licensing for receiving } \\
\text { WEEE by the generators; } \\
\text { Possible damage to health of people involved in recycling of WEEE and } \\
\text { environmental } \\
\text { contamination due to ineffective supervision; - High marginal costs of } \\
\text { electronics producers with possible via transfer pricing. }\end{array}$ \\
\hline
\end{tabular}

Table 3: Scenario analysis of PNRS in Brazil in the management of WEEE.

The scenario analysis shows an overview of PNRS pathologies that can be interpreted similarly to $[2,19,36]$ suggesting that much can be synonymous with nothing. Applicability of Economic Theory of Games in WEEE Management in Brazil

Facing the increasing challenges regarding the continuity of economic growth of nations, there are necessary strategies to maximize gains and minimize economic losses. Considering the policies and practices on the management of WEEE already highlighted in Section 2 and the involvement of countries on five continents, it is possible to see opportunities to benefit from economies of scale in managing WEEE to take advantage of WEEE recyclers being competitors in the same market. In other words, given the obligation of producers of electrical and electronic equipment to collect waste from their products, to transport back to the factory and to dispose of them, such as recycling cooperatives in Brazil, for their interest in collecting, transporting and recycling the residues given their economic potential. However, there may be possibilities for conflicts of interest between consumer electronics manufacturers who are determined to affect RL and recycling cooperatives who are determined to collect and recycle as much as possible and without selectivity. This issue also enables the application of present concepts in economic theory games involving profits and responsibility for the life cycle of electronic products "from cradle to grave". In Brazil, mandatory RL for electronics producers and 
forecasting use of economic instruments in managing WEEE provide an opportunity for competitive moves comparable to strategic games.

\section{Simulation of a Scenario Made by a Consumer Electronics Manufacturer and a Cooperative of Collectors/Recyclers of WEEE}

Considering a cooperation of collectors/recyclers as players whose interest is larger profits without concern for the brand of each WEEE collected, an electronics producer in Brazil, pursuant to Law No. $12,305 / 2010$, should practice RL and position the dimensions of equilibrium strategies to achieve the optimum point of the Game based on a set of decisions such that each player reaches or thinks he/she has reached the goal, according to their objective function. Because both players are subject to the same PNRS, an optimal allocation of WEEE can be made in the form of Pareto's Equilibrium model that establishes an optimal solution to maximize the welfare of the players and, according to the Nash Bargaining model, attempts a more balanced optimal solution.

Thereby, in case the government allows the establishment of a perfectly competitive market for WEEE, as each player maximizes their welfare, they cooperate to maximize each other's welfare as they follow the precepts of perfect competitive markets [38,39]. Against the previously described backdrop about the environment of electronics producers and consequently WEEE generators - a variable sum of Cooperative Game would be recognized with a competition between the players and a goal to bring them all together.

It is worth mentioning that Ref. [26] notes that externalities can be eliminated through private negotiations without governmental regulations, as long as the property rights of the individuals involved in the negotiations are defined. This principle is established in the Coase Theorem [11] in which the participating players of WEEE management could freely negotiate and achieve a mutual benefit (Cooperative Game). According to the Theorem, the result of this game will be efficient and not dependent on how the right to property is defined. The applicability of game theory in WEEE management in Brazil is based on a scenario of cooperation between those with an obligation, by force of law, to practice RL, and those who are interested in collecting and recycling WEEE but who are not manufacturers (recycling cooperatives/recycling of WEEE, for example).

Such an obligation in case of negotiation between the parts should pursue the goal of achieving an optimal level of return/recycling of WEEE to the manufacturer/recycler, assuming all conditions of perfectly competitive market. Thus, the optimal level of WEEE management will initially be one in which the marginal benefit of recycling is equal to the marginal external cost imposed on the electronics manufacturer, which would no longer practice RL due to the action of the collector agent and recycling of WEEE (nonmanufacturer). The aim was to evaluate the theory described above to manage WEEE and compare the results obtained by the two models (Pareto's Equilibrium and Nash's Equilibrium). Then following, there is a scene with two players. Based on the Coase Theorem, considering the first model (Pareto's Equilibrium) based on negotiation between the parts, the establishment of property rights on WEEE will determine who will take the first step towards achieving the socially desired point.

Hypothetically, consider the existence of a producer of electrical and electronic equipment and a cooperative of collectors/recyclers of WEEE called "A" and "B". For the electronics producers, their interest would be to practice RL, but this "move" implies financial damage to the cooperative of collectors/recyclers. Otherwise, the cooperative would more efficiently gather and recycle WEEE, which would harm the manufacturer who must perform RL in WEEE by law.

To use the Coase Theorem in this, game, it is necessary to consider that the government only defines the ownership of WEEE, requiring the parts to only be compliant with the environmental goal of recycling WEEE and preserving the existence of the socioeconomic function of the cooperative of collectors/recyclers of WEEE. In this scenario, we consider the marginal external cost of electronics manufacturers (player "A") being an increasing function [40] related to the externalities caused by nonexecution of RL, such as loss of additional revenue and damage to certification agencies for the recognition of good environmental conservation practices. For the cooperatives (player "B"), the marginal private net benefit is a decreasing function [40] and has the marginal benefit of being the last unit mass collected and recycled equal to zero.

For simulation purposes, consider the following marginal cost/ benefit:

$$
\begin{aligned}
& \mathrm{MEgC}_{\text {manufacturer }} \text { 2.Q (1) } \\
& \mathrm{MNgPB}_{\text {cooperative }} \text { 1203. } Q(2)
\end{aligned}
$$

Where,

$\mathrm{MEgC}_{\text {manufacturer }}$ Marginal External Cost of electronics manufacturer USD/ton

$\mathrm{MNgPB}_{\text {Cooperative }}$ Marginal Net Private Benefits of cooperative of collectors/recyclers of WEEE USD/ton

Q Quantity of WEEE (ton)

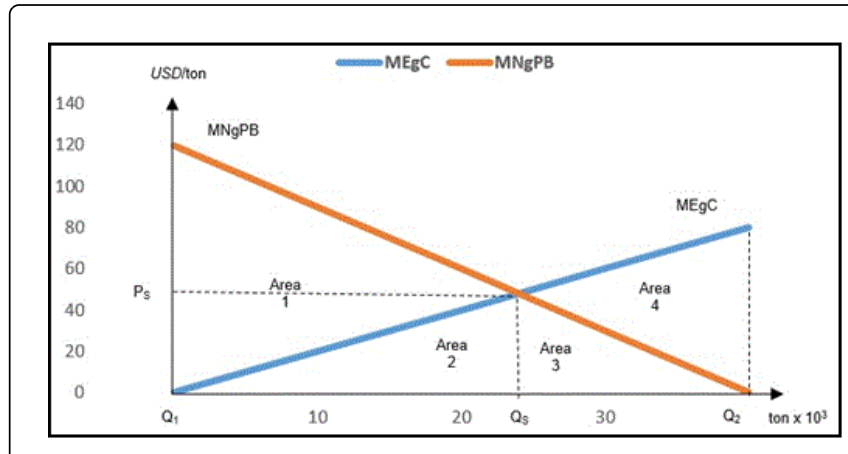

Figure 2: Illustrates the possibilities existing in negotiation scenarios, Graphic demonstration of possible scenarios during negotiation between "A" and "B".

In Figure 2, consider an interval of any time. Based on (1) and (2), there is: $\mathrm{Q}_{1}=0$ tons of WEEE; $\mathrm{Q}_{2}=40 \times 10^{3}$ tons of WEEE; and $\mathrm{Q}_{\mathrm{S}}=24 \times$ $10^{3}$ tons of WEEE.

The analysis of the situation described in Figure 2 suggests that in the case of property rights of WEEE of cooperatives of collectors/ recyclers (player "B"), their initial interest will be to recycle $40 \times 10^{3}$ tons of WEEE, as this leads to the maximum Total Benefit. Nevertheless, the maximum Total Benefit of player "B" leads to the Maximum Total Cost for player "A". While player "A" intends to stay in the market, he/she will search for player "B" who is the holder of WEEE property rights to propose negotiations. 
While the equilibrium point obtained in the proposed essay is equal to $\mathrm{Q}_{S}=24 \times 10^{3}$ tons of WEEE, the electronics manufacturer (player "A") will be willing to financially compensate player "B" by paying up to the equivalent to the sum of the areas 3 and 4 to ensure the reduction of recycling by player "B" $\mathrm{Q}_{2}$ level to $\mathrm{Q}_{S}$. This situation will ensure that the electronics producer practices $\mathrm{R}_{\mathrm{L}}$; however, player "B" fails to gain the equivalent to area 3 in terms of Total Benefit. Willingness to negotiate by player "B", holder of WEEE property rights, stems from the fact that he/she can increase their Total Benefit by benefiting from the player "A's" interest to remain on the market. For this reason, player "B" will be willing to receive any amount at or above area 3 that strengthens the coexistence of the players and promotes the achievement of Pareto's Optimum.

On the other hand, in a scenario where the WEEE property rights are given to player "A", the initial interest will be to not allow any recycling of WEEE by the cooperative of collectors/recyclers of WEEE because this leads to a Total Cost External of zero. However, in this case, the Total Benefit for player "B" will be zero, which puts him/her out of business. Because player "B" intends to stay in the market, he/she will search for player "A" who is now holder of WEEE property rights to propose negotiations. While the equilibrium point obtained in the proposed essay is $\mathrm{Q}_{S}=24 \times 10^{3}$ tons of WEEE, the cooperative (player "B") will be willing to financially compensate player "A" to the equivalent of the sum of areas 1 and 2 to ensure an increase in the recycling of WEEE, by the cooperative, of $\mathrm{Q}_{1}$ to $\mathrm{Q}_{s}$. This situation will ensure the survival of the cooperative in the market; however, the problem is that player " $A$ " in $Q_{S}$ has a total cost equivalent to External Area 2.

The will of player "A" to accept such a condition arises from the fact that it is possible for him/her to receive greater or equal financial compensation to their total costs caused by the collection cooperative operations of collection/recycling of WEEE. Therefore, player "A" would be willing to receive any amount equal to or superior to area 2, making up the difference by partially performing RL and thereafter earning profits from recycling its WEEE.

Considering the same scenario, but now using the Nash Bargaining model (Nash's Equilibrium), a different economic result was found compared with simple negotiation between the parts. However, the result is also an optimum point, considered the Pareto Efficient, which is more balanced (Santos). The economic analysis is shown below, considering the cost variables and overall benefit:

$T C E_{\text {manufacturer }}$

$B T L P_{\text {cooperative }}$

Where,

\section{TCE manufacturer: Total External Costs of electronics USD}

BTLP cooperative: Total Benefit Net Private of cooperative of collectors/recyclers of WEEE USD

\section{Q: Quantity of WEEE tons}

In this case, as a requirement at the start of negotiation, player A (electronics manufacturer) will obtain a Total Cost External lower than USD $1,600.00$ because this is the maximum that can be achieved if granted the right to the property of WEEE [ton] to the cooperative of collectors/recyclers.
Therefore, USD 1,600.00 is a point of disagreement for player A. Player B (cooperative of collectors/recyclers) will require a Total Benefit Net Privatenon-negative in the early part of negotiation. For this reason, the disagreement point is $\mathrm{TBNP}=0$ for player $\mathrm{B}$. Then, using the Nash Bargaining model, the problem is formalized, as follows

$\max \mathrm{z}=(1600-$ TCE manufacturer) BTLPcooperative

Subject to:

TCEmanufacturer $\geq Q^{2}(6)$

BTLPcooperative $\leq 120$ Q-3/2 Q $2(7)$

TCEmanufacturer $\leq 1600(8)$

BTLPcooperative $\geq 0$ (9)

$\mathrm{Q} \geq 0$ (10)

By using simple devices, we can adapt this model (5) -(10) to a convex optimization formulation:

Subject to:

$$
\begin{aligned}
& \exp (v) \leq 1600-Q^{2} \\
& \exp (u) \leq 120 Q-\frac{3}{2} Q^{2} \\
& 1600-\mathrm{Q}^{2} \geq 0 \\
& \mathrm{Q} \geq 0
\end{aligned}
$$

Solving the latter model by the Excel Solver, we arrive at a value of $\mathrm{Q}=20$ that corresponds to $20 \times 10^{3}$ tons of WEEE. This value is a Pareto efficient outcome. Because player "A" intends to stay in the market, he/she will search for player "B", the holder of WEEE property rights to propose negotiations. With an equilibrium point of $20 \times 10^{3}$ tons of WEEE, the electronics manufacturer (player A) will be willing to financially compensate player $\mathrm{B}$ by paying up to the equivalent $1600-\mathrm{Q}_{2}=\mathrm{USD} 1.200 .000,00$ to ensure the reduction of recycling by player $\mathrm{B}$ from $40 \times 10^{3}$ tons of WEEE to $20 \times 10^{3}$ tons.

In contrast, the other scenario in which the WEEE property rights are given to player $\mathrm{A}$, the cooperative (player $\mathrm{B}$ ) will be willing to financially compensate player A to the equivalent $120 \mathrm{Q}-3 / 2 \mathrm{Q}_{2}=\mathrm{USD}$ $1.800 .000,00$ to ensure an increase in WEEE recycling by the cooperative from 0 tons to $20 \times 10^{3}$ tons of WEEE.

\section{Discussing the Results}

Comparing the two WEEE management strategies, the Nash Bargaining model of negotiating in Table 4 provides a more efficient solution to achieve an equilibrium point with less recycled WEEE. This solution offers lower total costs to the game when summing the charges of player's "A" and "B" when granting proprietary rights for WEEE. The likely explanation for this result is that neither player can increase his/her level of payoff without the other player decreasing his/her level in this solution offered by Pareto's Optimum, and it is therefore necessary to find a payoff solution that is fair to both.

\begin{tabular}{|l|l|l|}
\hline Property Right & $\begin{array}{l}\text { Pareto's Optimum } \\
\text { [USD] }\end{array}$ & $\begin{array}{l}\text { Nash's Bargain } \\
\text { [USD] }\end{array}$ \\
\hline $\begin{array}{l}\text { Electronics manufacturer } \\
\text { (outgoing) }\end{array}$ & $1,024,000.00$ & $1,200,000.00$ \\
\hline
\end{tabular}




\begin{tabular}{|l|l|l|}
\hline $\begin{array}{l}\text { Collectors/Recyclers } \\
\text { cooperative } \\
\text { (outgoing) }\end{array}$ & $2,016,000.00$ & $1,800,000.00$ \\
\hline Total Outgoing & $3,040,000.00$ & $3,000,000.00$ \\
\hline Equilibrium Quantity[ton] & 24,000 & 20,000 \\
\hline
\end{tabular}

Table 4: Comparing between the Nash Bargaining and Pareto Optimal Models.

In this situation, the Nash Bargaining model not only satisfies the Pareto's Optimum axiom but also satisfies the other three axioms, including symmetry (ensuring the inclusion of all relevant parameters for negotiation), independence (of irrelevant alternatives in the negotiation process) and invariance (for linear transformations that ensures that the solution should be independent of any measure scale adopted) [27].

\section{Conclusions and Suggestions for Continuing Research}

In this simulation, the use of Economic Game Theory, combined with application of the Coase Theorem, was promising at creating opportunities to achieve socially optimal economic results, eliminating the externalities from a negotiation between players who will act in a cooperative manner. When evaluating the economic results of the negotiation essay between a practitioner RL electronics manufacturer of WEEE and a cooperative of collectors/recyclers of WEEE using Game Theory, it is possible to conclude that the scope of the environmental goal of recycling an amount "Qs" of WEEE is always achieved because the right of ownership of such waste is defined, and there is no need for government intervention.

The application of game theory in the matter of waste electrical and electronic equipment also highlights the opportunity of establishing an agreement between two parties that have the same interest, but for different reasons. In the case under study, the manufacturer of electrical and electronic equipment interested in collecting, transporting and allocating the waste of its products by virtue of Brazilian environmental legislation; and the cooperative of waste pickers/recyclers, interested in gaining economic and social gain with their recycling. Additionally, the use of the Nash Bargaining model provides a more efficient solution than the Pareto's Optimum for cooperation between the players, presents a balanced recycled WEEE and generates a lower total cost for both players, regardless of who owns the WEEE property rights.

Despite the economic outcomes of negotiations between the parties in the outlined scenario, there are difficulties in practically implementing the Coase Theorem in WEEE management in Brazil because the rights are not absolute but are attenuated, circumscribed to the law. For this reason, applying the theory of cooperative games and pursuing Pareto's Equilibrium, through consortia with the Coase Theorem, would require changes in Law No. 12,305/2010.

Another limitation is the possibility of transaction costs that cannot be negotiated between the players (agents), thereby reducing the chance of achieving socially desired results. Finally, the negotiated solution can be distorted in the final economic results, particularly in cases where more players are brought into the negotiating stage among the unbalanced "politic forces".
In the future, further studies on WEEE management strategies in Brazil should promote studies in Game Theory on Pigouvian Taxes and the Theory of Pollution Certificates [41] to compare costs and benefits using regulatory instruments for economic tools and to achieve economic and environmental efficiency.

\section{References}

1. Conti BMD, Prates DM, Plihon D (2014) The hierarchy of currencies and its implications for peripheral countries exchange and interest rate dynamics and economic policy. Econ Soc 23: 341-372.

2. Oliver-Sola J (2010) Prosperity without Growth? -The transition to a sustainable economy. J of Clean Prod 18: 596-597.

3. Aziz NAA, Yau FS, San OT, Attan H (2015) A Review on Green Integration into Management Control System. PSBS 172: 435-441.

4. Jabareen Y (2008) A new conceptual framework for sustainable development. Enviro Devel Sust 10: 179-192.

5. Smith R (2012) Economic geography and innovation clusters. Eco Analy $1: 1-11$.

6. Naini SGJ, Moini A, Rezaee MJ (2013) Nash bargaining game model for two parallel stages process evaluation with shared inputs. IJAMT 67: 475-484.

7. Marins FAS, Muniz Jr J, Oliveira UR, Araujo MVF (2015) Cost Assessment and Benefits of Using RFID in Reverse Logistics of Waste Electrical \& Electronic Equipment (WEEE). Proc Com Sci 55: 688-697.

8. Silva AF, Miranda RC, Marins FAS (2015) A Fuzzy-DEA-game model for uncertainty in production strategies. RAE 55: 78-94.

9. Arthmar R (2015) Vilfredo Pareto, Manual of Political Economy, A critical and variorum edition, Oxford University Press, pp: 1-664.

10. Carfi D, Schiliro D (2011) Crisis in the Euro Area: Competitive Game Solutions as New Policy Tools. TPREF 1: 23-36.

11. Coase RH (1960) The Problem of Social Cost. J of Law and Eco 3: 1-44.

12. Kolias K, Hahladakis JN, Gidarakos E (2014) Assessment of toxic metals in waste personal computers. Waste Manag 34: 1480-1487.

13. Atasu A, Subramanian R (2012) Extended producer responsibility for ewaste, Individual or collective producer responsibility? Prod and Oper Manag 21: 1042-1059.

14. Ongondo FO, Williams ID, Cherrett TJ (2011) How are WEEE doing? A global review of the management of electrical and electronic wastes. Waste Manag 31: 714-730

15. Galaz V, Biermann F, Folke C, Nilsson M, Olsson P (2012) Global environmental governance and planetary boundaries: an introduction. Ecol Eco 81: 1-3.

16. Becker GS, Philipson TJ, Soares RR (2005) The Quantity and Quality of Life and the Evolution of World Inequality. American Econ Rev 95: 277-291.

17. Greenpeace (2009) Where does e-waste end up?

18. Townsend TG (2011) Environmental Issues and Management Strategies for Waste Electronic and Electrical Equipment. JAWMA 61: 587-610.

19. Demajorovic J, Migliano JEB (2013) National solid waste policy and its implications for microcomputers reverse logistics chain in Brazil. Ges \& Regio 29: 64-80.

20. Herat S, Agamuthu P (2012) E-waste: a problem or an opportunity? Review of issues, challenges and solutions in Asian countries. Waste Manag \& Res 30: 1113-1129.

21. Dwivedy M, Suchde P, Mittal RK (2015) Modeling and assessment of ewaste take-back strategies in India. Resour Conser and Recyc 96: 11-18.

22. Lifset R, Lindhqvist $T$ (2008) Producer responsibility at a turning point? J of Indus Eco 12: 144-147.

23. Narain, U, Margulis S, Essam T (2011) Estimating costs of adaptation to climate change. Clim Poli 11: 1001-1019.

24. Costa SST (2006) Introduction to environmental economics. PUCRS 16: 308-317. 
Citation: Araujo MV, Silva Marins FA, Santos MA, de Oliveira UR, Muniz Junior J (2017) Game Theory Applied in the Management of Electric and Electronic Equipment Waste in Brazil. Adv Recycling Waste Manag 2: 125. doi:10.4172/2475-7675.1000125

Page 9 of 9

25. Kronenberg J, Hubacek K (2013) Could payments for ecosystem services create an "ecosystem service curse". Ecol and Soci 18: 10.

26. Cassidy J (2013) Ronald Coase and misuse of the economy. REI 15: 321-325.

27. Santos MARD (2014) Estimation of strategic goals through data envelopment analysis and model of Nash Bargaining: application in health public

28. Caleman SMDQ, Zylbersztajn D (2013) Organizational failures: typology, determinants and a proposed theoretical model. Organi and Soc 20 261-282.

29. Banco Mundial (2015) Produto Interno Bruto PIB do Brasil (Gross Domestic Product of Brazil).

30. Vaishnav D, Diwan R (2013) E-Waste management-An overview. RRST 5 92-97.

31. Bachi MH (2013) Waste Technology: The relationship of the Electronics Waste and the Law in Brazil. RBGA 7: 1-5.

32. Schluep M, Muller E, Hilty LM, Ott D, Widmer R (2013) Insights from a decade of development cooperation in e-waste management. In ICT for Sustainability: Proceedings of the First International Conference on Information and Communication Technologies for Sustainability, pp: 45-51.

33. Gomes ER (2012) Opportunities and Dilemmas of Solid Waste Treatment in Brazil in Light of National Solid Waste Policy. CRISD 14: 100-114.
34. Jones SM, Luisetti T, Turner RK, Fisher B (2011) Ecosystem valuation: some principles and a partial application. Environmetrics 22: 675-685.

35. Manhart A (2011) International Cooperation for Metal Recycling From Waste Electrical and Electronic Equipment. J of Indust Eco 15: 13-30.

36. Rowley HV, Peters GM, Lundie S, Moore SJ (2012) Aggregating sustainability indicators: beyond the weighted sum. J of Enviro Manag 111: 24-33.

37. Nash J (1953) Two-Person Cooperative Games. Econometrica 21: 155-162.

38. Brand U (2012) Green economy-the next oxymoron? No lessons learned from failures of implementing sustainable development. GAIA-EPSS 21: 28-32.

39. Planas XM, Seccia G (2011) Consumer default with complete markets: risk-based pricing and finite punishment. School of Social Sciences. Eco Theo 56: 549-583.

40. Godoy SGMD, Saes MSM (2015) Cap-and-trade and project-based framework: how do carbon markets work for greenhouse emissions reduction? Ambie and Socie 18: 135-154.

41. Junior AH, Araujo MVF, Sabbadini FS (2014) Theory of Pollution Certificates: Policy Developments and Industrial Applications. GJRE 13: 29-36. 